\title{
CARACTERÍSTICAS FÍSICAS E QUÍMICAS DE SUBSTRATOS PARA PRODUÇÃO DE MUDAS DE Ilex paraguariensis St. Hil. ${ }^{1}$
}

\author{
Ivar Wendling 2 , Daniel Guastala ${ }^{3}$ e Renato Dedecek ${ }^{2}$
}

\begin{abstract}
RESUMO - Neste trabalho, objetivou-se avaliar as propriedades físicas e químicas de diferentes materiais e suas combinações, bem como sua influência na produção de mudas de erva-mate em tubetes plásticos. O trabalho foi conduzido no viveiro da Empresa Baldo S.A., em São Mateus do Sul, PR. Utilizaram-se seis materiais: esterco bovino curtido, serragem semidecomposta, palito de erva-mate picado, terra de subsolo, substrato comercial à base de casca de pinus e húmus de minhoca, com os quais foram formulados 14 tratamentos. Os resultados indicaram que os tratamentos que continham serragem, palito de erva-mate e, principalmente, esterco bovino, além de serem mais econômicos, mostraram bons resultados na qualidade das mudas produzidas. Dentre esses tratamentos, aquele composto de $40 \%$ de esterco bovino e $60 \%$ de serragem se destacou, em vista da boa relação custo-benefício apresentada e da sua facilidade de preparo. As características químicas dos substratos não interferiram nas suas características físicas, assim como a influência das características físicas na produção de mudas de erva-mate depende da variável analisada.
\end{abstract}

Palavras-chaves: Erva-mate, propagação sexuada e propagação de plantas.

\section{PHYSICAL AND CHEMICAL CHARACTERISTICS OF SUBSTRATES FOR THE PRODUCTION OF Ilex paraguariensis St. Hil. SEEDLINGS}

\begin{abstract}
This work aimed to evaluate the physical and chemical properties of different materials and their compositions, as well as their efficiency in the production of Ilex paraguariensis seedlings in plastic tubes. The work was conducted at the Baldo S.A. Company nursery in São Mateus do Sul, PR, Brazil. Six materials were used to formulate 14 treatments: cattle manure, semi-decomposed sawdust, Ilex paraguariensis chopped stems, underground earth, commercial substrate based on pinus bark and earthworm humus. The results indicated that the treatments containing sawdust, Ilex paraguariensis stems and mainly cattle manure, besides being more economical, produced good quality seedlings. The treatments consisting of $40 \%$ cattle manure and $60 \%$ sawdust stood out because of the good cost-benefit ratio and the easiness of preparation. Substrate chemical characteristics did not affect the physical characteristics, as well the influence of physical characteristics on Ilex paraguariensis seedling production depends on the analyzed variable.
\end{abstract}

Keywords: Mate, sexual propagation and plant propagation.

\section{INTRODUÇÃ̃O}

A produção de mudas de espécies florestais, em quantidade e qualidade, é uma das fases mais importantes para o estabelecimento de povoamentos, com repercussão sobre a sua produtividade e qualidade.
Nesse sentido, muitos esforços têm sido realizados para melhorar a qualidade e reduzir os custos de produção das mudas.

Em se tratando da implantação de uma cultura perene, um ponto importante a ser considerado diz

\footnotetext{
${ }^{1}$ Recebido em 12.07.2006 e aceito para publicação em 15.12.2006.

${ }^{2}$ Embrapa Florestas, Estrada da ribeira, km 111, Guaraituba, 83411-000, Colombo, PR. E-mail:<ivar@cnpf.embrapa.br>.

${ }^{3}$ Engenheiro Florestal, Unicentro, PR 153 km 7 - Riozinho, 84500-000, Irati, PR. E-mail:<guastaroots@ yahoo.com.br>.
} 
respeito à qualidade das mudas que, por sua vez, dentre outros fatores, é função da qualidade do substrato que as sustentam (MOSELE et al., 1994). Para Ferron (1997), o sucesso na obtenção de mudas de erva-mate de alto padrão está relacionado com a composição do substrato. Segundo Fonseca (2001), na escolha de um substrato se devem observar, principalmente, suas características físicas e químicas e a espécie a ser plantada, além dos aspectos econômicos como baixo custo e disponibilidade.

Para a produção de mudas de erva-mate em vasos com capacidade para $120 \mathrm{~cm}^{3}$, Santin et al. (2004), testando o bagaço de cana, a casca de pinus, o vermicomposto e o esterco de gado curtido, em adição ao solo, como componentes para substrato, concluíram que o melhor tratamento foi composto por $90 \%$ de solo e $10 \%$ de vermicomposto.

O nível de eficiência dos substratos para germinação de sementes e iniciação radicular, entre outras características, está associado à sua capacidade de aeração, drenagem, retenção de água e disponibilidade de nutrientes (GONÇALVES e POGGIANI, 1996). Como não é fácil encontrar material puro com as características ideais para um substrato, devem ser feitas misturas, melhorando suas propriedades físico-químicas (SANTOS et al., 2000).

Devido às várias dificuldades encontradas na produção de mudas de erva-mate de boa qualidade, Sturion (1988) citou a necessidade de trabalhos visando à adequação de substratos, nutrição e recipientes. Segundo Lourenço et al. (2000), em viveiros de produção de mudas de erva-mate tem sido utilizado solo superficial e, ou, terra de subsolo para composição dos substratos. Entretanto, a pressão para utilização de substratos que não agridam o meio ambiente para a sua extração e que sejam oriundos de resíduos renováveis é cada vez maior. Em relação a recipientes para produção de mudas, Freitas et al. (2006) salientaram que os tubetes apresentam uma série de vantagens, como a facilidade operacional, resultante da mecanização, redução do uso de mão-de-obra e melhores condições de trabalho, maximizando a produção.

Em vista da grande disponibilidade de resíduos agroindustriais que indicam a possibilidade de constituírem substrato adequado para a produção de mudas de erva-mate e a necessidade de estudos visando à sua utilização em tubetes, este trabalho objetivou avaliar as características físico-químicas de diferentes materiais e suas combinações, bem como sua influência na produção de mudas de erva-mate de qualidade em tubetes plásticos.

\section{MATERIAL E MÉTODOS}

O experimento foi conduzido no viveiro da Empresa Baldo S.A., em São Mateus do Sul, PR, com sementes provenientes de matrizes do mesmo município. Depois de coletadas, as sementes foram estratificadas em areia por seis meses (MEDEIROS, 1998). A semeadura foi realizada em sementeiras, contendo terra de subsolo, no final de janeiro de 2004, e posteriormente, ao atingirem de 2 a $4 \mathrm{~cm}$ de altura, as mudas foram repicadas para tubetes médios $\left(100 \mathrm{~cm}^{3}\right.$ de capacidade) e cobertas com sombrite (capacidade de interceptação da luz de $70 \%$ ), onde permaneceram durante todo o experimento.

Para a composição dos 14 tratamentos foram utilizados: esterco de gado confinado curtido; serragem de pinus semidecomposta; palito de erva-mate picado (de 1 a $3 \mathrm{~mm}$ ); terra de subsolo; substrato comercial à base de casca de pinus; e húmus de minhoca (Tabela 1). Os materiais de cada tratamento foram misturados manualmente. Para a padronização da fertilização foi usado adubação de base, de modo que todos os tratamentos atingissem $133 \mathrm{~g}$ de N, $465 \mathrm{~g}$ de $\mathrm{P}_{2} \mathrm{O}_{5}$ e $266 \mathrm{~g}$ de $\mathrm{K}_{2} \mathrm{O}$ por $\mathrm{m}^{3}$ de substrato. Antes da adição desses nutrientes, foram coletadas amostras para realização de análises químicas e físicas dos substratos. Avaliou-se também o custo de produção ou aquisição dos substratos.

Para as análises físicas, foi determinada a quantidade de substrato por tubete $\left(50 \mathrm{~cm}^{3}\right.$ de capacidade), para reproduzir a mesma densidade nos anéis metálicos de $5,3 \mathrm{~cm}$ de diâmetro por $3 \mathrm{~cm}$ de altura. Nessas amostras foram determinadas as seguintes características físicohídricas: porosidade total (umidade de saturação), macro e microporosidade e a curva de retenção de umidade $(-3,-6,-10,-100$ e $-1500 \mathrm{kPa})$, conforme metodologia descrita em Embrapa (1997). Com base nesses dados, foram estabelecidas a porosidade de aeração (entre a umidade de saturação e a umidade a $-3 \mathrm{kPa}$ ) e a água disponível (entre $-3 \mathrm{kPa}$ e $1.500 \mathrm{kPa}$ ). As análises das características químicas do substrato seguiram a metodologia para análise da fertilidade do solo, conforme métodos descritos em Embrapa (1997). 
Tabela 1 - Material utilizados para formulação dos tratamentos de substratos (base volume/volume)

Table 1 -Materials used for formulation of substrate treatments (base volume/volume)

\begin{tabular}{ccccccc}
\hline Tratamento & SC & EB & SE & PE & TS & HM \\
\hline T 1 & $100 \%$ & & & & & \\
T 2 & $70 \%$ & & & $30 \%$ & & \\
T 3 & $60 \%$ & & $20 \%$ & $20 \%$ & & \\
T 4 & $60 \%$ & & $10 \%$ & $20 \%$ & $10 \%$ & \\
T 5 & $60 \%$ & & $40 \%$ & & & \\
T 6 & $60 \%$ & & $20 \%$ & & $20 \%$ & \\
T 7 & & $30 \%$ & $40 \%$ & $30 \%$ & & \\
T 8 & & $30 \%$ & $30 \%$ & $30 \%$ & $10 \%$ & \\
T 9 & $40 \%$ & $60 \%$ & & & \\
T1 & & $40 \%$ & $40 \%$ & & $20 \%$ & \\
T1 1 & & & $40 \%$ & $30 \%$ & & $30 \%$ \\
T12 & & & $30 \%$ & $30 \%$ & $10 \%$ & $30 \%$ \\
T13 & & & $60 \%$ & & & $40 \%$ \\
T14 & & & $40 \%$ & & $20 \%$ & $40 \%$ \\
\hline
\end{tabular}

$\mathrm{SC}=$ substrato comercial à base de casca de pinus; $\mathrm{EB}=$ esterco bovino de gado confinado curtido; $\mathrm{SE}=$ serragem semidecomposta; $\mathrm{PE}=$ palito de erva-mate picado e peneirado de 1 a $3 \mathrm{~mm} ; \mathrm{TS}=$ terra de subsolo; e $\mathrm{HM}=$ húmus de minhoca

O delineamento estatístico utilizado foi de blocos ao acaso, com cinco repetições e 40 mudas por repetição. Avaliou-se a mortalidade aos 15 e 30 dias após a repicagem e, aos seis meses após a repicagem, o diâmetro do colo, a altura, a facilidade de retirada do tubete, a agregação das raízes ao substrato e o tempo gasto em horas para a limpeza de plantas indesejáveis em 1.000 mudas de erva-mate.

Para a avaliação da facilidade de retirada das mudas do tubete, usaram-se como padrão três batidas na parte superior (boca) dos tubetes e, em razão da facilidade de retirada, foram atribuídos pesos de zero (dificuldade máxima) a 10 (grande facilidade). Para avaliação da agregação das raízes ao substrato, as mudas sem os tubetes foram soltas em queda livre a um metro do solo, recoberto por brita. Ao torrão foi dada uma nota de acordo com a escala de zero a 10 , sendo zero para a muda totalmente esboroada e 10 para a muda íntegra. As duas avaliações supracitadas foram realizadas por uma pessoa treinada previamente na metodologia ora desenvolvida e apresentada.

Os dados foram transformados de acordo com o tipo de avaliação e a necessidade, sendo o porcentual de mortalidade por arcseno $\sqrt{\left(\frac{X}{100}\right)}$, a facilidade de retirada das mudas do tubete e a agregação das raízes ao substrato por $\sqrt{X}$. As médias foram comparadas pelo teste de Scott-Knott a $5 \%$ de probabilidade.

\section{RESULTADOS E DISCUSSÃO}

Os custos de obtenção variaram de $\mathrm{R} \$ 13,00$ (tratamentos com esterco, serragem, palito de ervamate e terra de subsolo) a $\mathrm{R} \$ 90,00$ (tratamentos com substrato comercial em sua composição), para cada $\mathrm{m}^{3}$ de substrato (Figura 1). Assim, os tratamentos T1 a T6, que continham substrato comercial à base de casca de pinus; e T11 a T14, que continham húmus de minhoca, tiveram custos superiores aos demais (T7, T8, T9 e T10), com esterco bovino, serragem, palito de erva-mate e terra de subsolo em sua composição.

A utilização de resíduos da agroindústria como componentes para substratos pode propiciar a redução de custos (SANTOS et al., 1994), além de ser uma atitude ambientalmente correta. Isso foi claramente verificado, uma vez que o esterco bovino, a serragem e o palito de erva-mate resultaram em custos de substratos mais baixos que os demais.

Na Tabela 2 são apresentados os resultados das características físicas e químicas dos diferentes tratamentos estudados e, para algumas, a comparação com a classificação proposta por Gonçalves e Poggiani (1996). Segundo essa classificação, os valores de densidade global ou aparente são considerados baixos para os tratamentos T1 ao T5, T7 ao T9 e T11 e médios para os tratamentos T6, T10 e T12 ao T14. De maneira geral, os tratamentos que continham substrato comercial apresentaram menor densidade, com exceção para o T6, em que a terra de subsolo (20\%) parece ter sido responsável pelo aumento dessa característica (Figura 2). Nos tratamentos T10 e T14, também a terra de subsolo (20\%) parece ter sido responsável pelo aumento da densidade, aliado ao húmus nos tratamentos T12 e T14. No tratamento T13, o aumento da densidade resultou exclusivamente do húmus. Disso resulta que a terra de subsolo em concentrações de $20 \%$, sem a presença de húmus e em $10 \%$ com húmus de minhoca, é responsável pelo aumento da densidade global dos substratos estudados. Valores de densidade global encontrados por Almeida (2005) para substratos à base de casca de pinus e vermiculita, casca de arroz carbonizada, fibra de coco e vermicomposto variaram de 0,21 a 0,37, indicando que diferentes misturas podem resultar em características semelhantes dos substratos.

R. Árvore, Viçosa-MG, v.31, n.2, p.209-220, 2007 


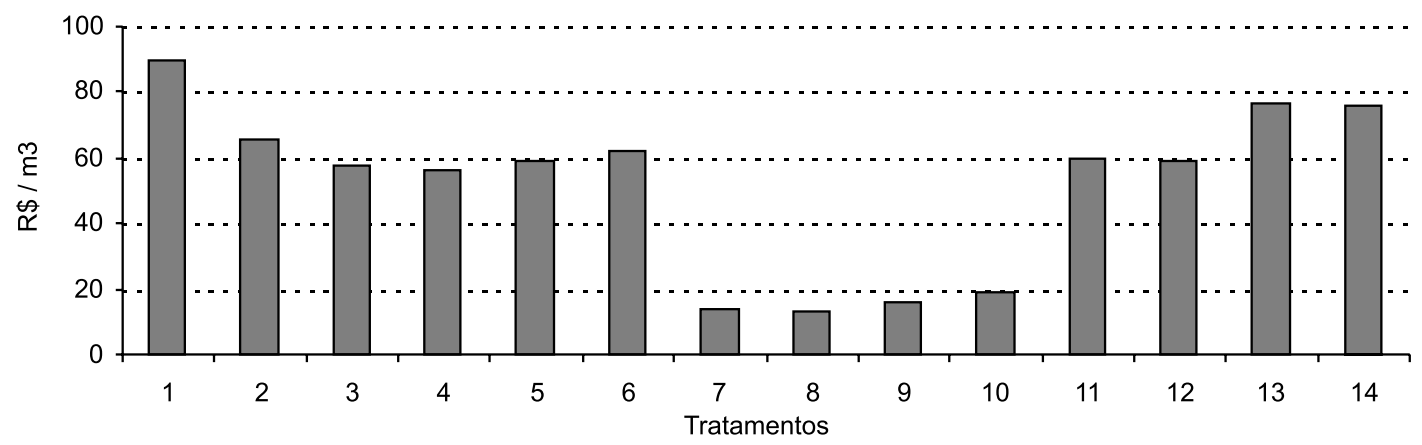

Figura 1 - Custo total de compra e, ou obtenção $\left(\mathrm{R} \$ / \mathrm{m}^{3}\right)$ dos substratos estudados (dólar 2,75).

Figure 1 - Total cost $\left(R \$ / m^{3}\right)$ of studied substrates (dollar 2,75).

Tabela 2 - Características físicas e químicas dos substratos estudados

Table 2 - Physical and chemical characteristics of substrates

\begin{tabular}{|c|c|c|c|c|c|c|c|c|c|c|c|c|c|c|}
\hline \multirow[t]{2}{*}{ Características } & \multicolumn{13}{|c|}{ Tratamentos } & \multirow[b]{2}{*}{$\mathrm{T} 14$} \\
\hline & $\mathrm{T} 1$ & $\mathrm{~T} 2$ & T3 & $\mathrm{T} 4$ & T5 & T6 & $\mathrm{T} 7$ & $\mathrm{~T} 8$ & T9 & $\mathrm{T} 10$ & $\mathrm{~T} 11$ & $\mathrm{~T} 12$ & $\mathrm{~T} 13$ & \\
\hline \multicolumn{15}{|l|}{ Físicas } \\
\hline $\begin{array}{l}\text { Densidade } \\
\text { global }\left(\mathrm{Kg} \mathrm{dm}^{-3}\right)\end{array}$ & $0,18 \boldsymbol{b}$ & $0,16 b$ & $0,18 \boldsymbol{b}$ & $0,23 \boldsymbol{b}$ & $0,19 b$ & $0,29 m$ & $0,17 \boldsymbol{b}$ & $0,20 \boldsymbol{b}$ & $0,21 \boldsymbol{b}$ & $0,30 \mathrm{~m}$ & $0,23 \boldsymbol{b}$ & $0,27 \boldsymbol{m}$ & $0,29 m$ & $0,33 \boldsymbol{m}$ \\
\hline $\begin{array}{l}\text { Porosidade } \\
\text { total }(\%)\end{array}$ & $74,5 \mathrm{~m}$ & $79,6 i$ & $79,0 \boldsymbol{i}$ & $77,2 i$ & $73,2 m$ & $68,1 \mathrm{~m}$ & $77,0 \boldsymbol{i}$ & $74,1 \mathrm{~m}$ & $73,4 m$ & $66,6 m$ & $72,6 m$ & $70,4 m$ & $73,3 \mathbf{m}$ & $71,8 \mathrm{~m}$ \\
\hline -macroporos(\%) & $48,4 a$ & $41,3 \boldsymbol{i}$ & $46,9 a$ & $45,5 a$ & $42,8 \boldsymbol{i}$ & $32,0 \boldsymbol{m}$ & $38,3 \boldsymbol{i}$ & $44,1 i$ & $41,9 \boldsymbol{i}$ & $41,0 \boldsymbol{i}$ & $38,3 \boldsymbol{i}$ & $39,7 \boldsymbol{i}$ & $39,9 \boldsymbol{i}$ & $33,4 m$ \\
\hline - microporos(\%) & $31,0 \boldsymbol{m}$ & $33,1 \mathrm{~m}$ & $31,9 m$ & $33,3 \boldsymbol{m}$ & $30,1 \boldsymbol{m}$ & $36,4 m$ & $31,2 \boldsymbol{m}$ & $35,0 \boldsymbol{m}$ & $33,4 m$ & $31,6 m$ & $33,4 m$ & $32,0 \boldsymbol{m}$ & $33,9 \boldsymbol{m}$ & $39,6 \boldsymbol{m}$ \\
\hline $\begin{array}{l}\text { Água disponível } \\
\left(\mathrm{mL} 100 \mathrm{~cm}^{-3}\right)\end{array}$ & 4,2 & 6,4 & 5,5 & 3,5 & 2,9 & 1,5 & 3,8 & 2,6 & 1,1 & 0,9 & 1,0 & 1,1 & 1,9 & 1,6 \\
\hline $\begin{array}{l}\text { Capac. máx. } \\
\text { ret.água }\left(\mathrm{mL} 100 \mathrm{~cm}^{-3}\right)\end{array}$ & $37,7 m$ & $43,2 \boldsymbol{m}$ & $42,2 \boldsymbol{m}$ & $37,5 m$ & $36,0 m$ & $30,7 m$ & $34,6 m$ & $32,1 \mathrm{~m}$ & $25,4 b$ & $21,7 \boldsymbol{b}$ & $30,2 \boldsymbol{m}$ & $29,5 \boldsymbol{b}$ & $32,0 \mathrm{~m}$ & $31,1 \mathrm{~m}$ \\
\hline \multicolumn{15}{|l|}{ Químicas } \\
\hline $\begin{array}{l}\text { Matéria orgânica } \\
\text { total }\left(\mathrm{g} \mathrm{Kg}^{-1}\right)\end{array}$ & 974,2 & 975,7 & 983,4 & 985,2 & 979,1 & 975,3 & 978,7 & 981,4 & 976,1 & 985,6 & 976,9 & 980,0 & 972,2 & 981,8 \\
\hline $\mathrm{N}$ total $\left(\mathrm{g} \mathrm{Kg}^{-1}\right)$ & 16,7 & 16,8 & 13,8 & 11,4 & 12,4 & 8,2 & 11,5 & 9,1 & 12,0 & 9,2 & 13,6 & 10,6 & 12,5 & 9,3 \\
\hline $\begin{array}{l}\mathrm{pH} \mathrm{em} \\
\mathrm{CaCl}_{2} 0,01 \mathrm{M}\end{array}$ & $4,8 \boldsymbol{b}$ & $5,2 m$ & $4,9 b$ & $5,0 \mathrm{~m}$ & $4,9 \boldsymbol{b}$ & $4,9 b$ & $5,7 m$ & $5,2 m$ & $5,3 \boldsymbol{m}$ & $5,3 \boldsymbol{m}$ & $5,3 m$ & $5,3 \boldsymbol{m}$ & $5,0 m$ & $4,8 \boldsymbol{b}$ \\
\hline $\begin{array}{l}\text { P Mellich } \\
\left(\mathrm{mg} \mathrm{dm}^{-3}\right)\end{array}$ & 1261,0 & 1310,4 & 790,4 & 533,0 & 525,2 & 340,6 & 286,0 & 327,6 & 421,6 & 239,2 & 283,4 & 314,6 & 379,6 & 221,0 \\
\hline $\mathrm{Na}^{+}\left(\mathrm{mg} / \mathrm{dm}^{-3}\right)$ & 104,0 & 104,0 & 78,0 & 52,0 & 52,0 & 52,0 & 104,0 & 130,0 & 182,0 & 208,0 & 26,0 & 25,0 & 26,0 & 24,0 \\
\hline $\begin{array}{l}\mathrm{K}^{+} \text {trocável } \\
\left(\mathrm{mol}_{\mathrm{c}} \mathrm{dm}^{-3}\right)\end{array}$ & $24,6 m$ & $38,6 i$ & $26,4 m$ & $24,6 \boldsymbol{m}$ & $15,9 m$ & $17,3 \boldsymbol{m}$ & $26,6 m$ & $29,3 \boldsymbol{m}$ & $28,6 m$ & $35,9 \boldsymbol{i}$ & $23,3 \boldsymbol{m}$ & $23,9 \boldsymbol{m}$ & $11,9 b$ & $13,1 \boldsymbol{b}$ \\
\hline $\begin{array}{l}\mathrm{Mg}^{2+} \text { trocável } \\
\left(\mathrm{mmol}_{\mathrm{c}} \mathrm{dm}^{-3}\right)\end{array}$ & $50,1 \mathrm{~m}$ & $83,7 \boldsymbol{i}$ & $27,2 \boldsymbol{b}$ & $42,1 b$ & $28,6 \boldsymbol{b}$ & $11,1 b$ & $25,6 b$ & $30,9 \boldsymbol{b}$ & $34,5 \boldsymbol{b}$ & $40,4 \boldsymbol{b}$ & $36,8 \boldsymbol{b}$ & $44,2 \boldsymbol{b}$ & $41,0 \boldsymbol{b}$ & $43,4 \boldsymbol{b}$ \\
\hline $\begin{array}{l}\mathrm{Ca}^{2+} \text { trocável } \\
\left(\mathrm{mmol}_{\mathrm{c}} / \mathrm{dm}^{-3}\right)\end{array}$ & $54,8 \boldsymbol{b}$ & $41,0 \boldsymbol{b}$ & $51,0 \boldsymbol{b}$ & $63,7 \boldsymbol{b}$ & $36,8 \boldsymbol{b}$ & $66,9 b$ & $61,0 b$ & $77,3 \boldsymbol{b}$ & $52,9 b$ & $78,7 \boldsymbol{b}$ & $70,1 b$ & $87,9 b$ & $83,6 \boldsymbol{b}$ & $86,5 \boldsymbol{b}$ \\
\hline $\begin{array}{l}\mathrm{Ca}^{2+}+\mathrm{Mg}^{2+} \\
\left(\mathrm{mmol}_{\mathrm{c}} / \mathrm{dm}^{-3}\right)\end{array}$ & 105,0 & 125,0 & 78,0 & 106,0 & 65,0 & 78,0 & 87,0 & 108,0 & 87,0 & 119,0 & 107,0 & 132,0 & 125,0 & 130,0 \\
\hline $\mathrm{Al}^{3+}\left(\mathrm{mmol}_{\mathrm{c}} \mathrm{dm}^{-3}\right)$ & 6,0 & 6,0 & 3,0 & 3,0 & 3,0 & 2,0 & 4,0 & 2,0 & 6,0 & 3,0 & 4,0 & 2,0 & 3,0 & 3,0 \\
\hline $\mathrm{H}^{+}+\mathrm{Al}^{3+}\left(\mathrm{mmol}_{\mathrm{c}} \mathrm{dm}^{-3}\right)$ & 62,0 & 42,0 & 32,0 & 31,0 & 28,0 & 34,0 & 24,0 & 31,0 & 28,0 & 37,0 & 29,0 & 32,0 & 38,0 & 52,0 \\
\hline
\end{tabular}

$\mathrm{b}=$ baixo; $\mathrm{m}=$ médio $\mathrm{a}=$ alto $; \mathrm{i}=$ adequado, com base na escala de valores para produção de mudas florestais em tubetes proposta por Gonçalves e Poggiani (1996).

Fonte: Laboratório de Solos e Nutrição Mineral, Embrapa Florestas, 2004.

Source: Laboratory of Soils and Mineral Nutrition, Embrapa Florestas, 2004.

\section{R. Árvore, Viçosa-MG, v.31, n.2, p.209-220, 2007}


Em relação à porosidade total (Tabela 2 e Figura 3), são observados valores médios para os tratamentos $\mathrm{T} 1$, T5, T6 e T8 ao T14 (de 68,5 a 74,4\%) e valores adequados para o T2 ao T4 e T7 (de 78,7 a 79,3\%). Pode-se supor que o palito de erva-mate foi o responsável pela elevação da porosidade total em todos os tratamentos que apresentaram valores indicados (mais altos) para essa característica. Nos demais tratamentos onde o mesmo material estava presente, a porosidade total foi diminuída a níveis médios pela presença de terra de subsolo (T8), húmus de minhoca (T11) e ambos (T12). Nessa característica, a escala de valores utilizada para interpretação foi similar aos resultados do teste de Scott-Knott.

Quando os valores de porosidade total são comparados com os recomendados por Carrijo et al. (2002) (acima de $85 \%$ ), percebe-se que os tratamentos estão abaixo dessa faixa. Já para o estudo realizado por Almeida (2005), com diferentes tratamentos e composições de substratos, as porosidades totais foram similares às obtidas no presente estudo, com exceção do tratamento composto somente de casca de arroz queimada com $87,6 \%$.
Em relação à macroporosidade (Figura 3), foram obtidos valores médios nos tratamentos T6 e T14, o que provavelmente seja decorrente da presença de terra de subsolo. Esses também são os únicos tratamentos em que os valores de macroporosidade são menores do que os de microporosidade, concordando com Gonçalves e Poggiani (1996). Valores de macroporosidade considerados adequados foram obtidos para T2, T5 e T7 a T13, tendo todos esses tratamentos o palito de erva-mate e, ou, a serragem em sua composição. Valores altos de macroporosidade foram obtidos para $\mathrm{T} 1, \mathrm{~T} 3$ e T4, todos contendo substrato comercial à base de casca de pinus, sendo $100 \%$ no T1 e $60 \%$ no T3 e T4, tendo nestes dois últimos também o palito de erva-mate associado com a serragem. Assim, podese supor que, dentre os materiais estudados, a casca de pinus foi a maior responsável pelo aumento da macroporosidade, sendo recomendada a sua utilização em concentrações abaixo de 70\%. Estatísticamente, percebeu-se ligeira superioridade da macroporosidade no tratamento T9, em seguida o T7 e T10 e por último, os demais tratamentos.

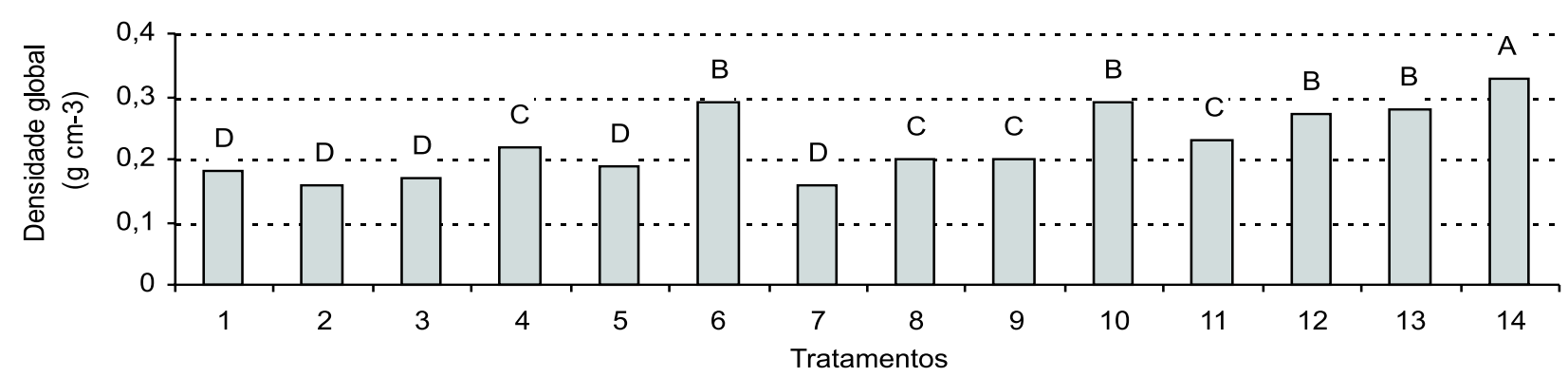

Figura 2 - Densidade global dos substratos estudados. Médias seguidas de uma mesma letra não diferem entre si pelo teste de Scott-knott a $5 \%$ de probabilidade.

Figure 2 - Global density values for studied substrates. Means followed by the same letters are not significantly different by the Scott-knott test, at $5 \%$ probability.

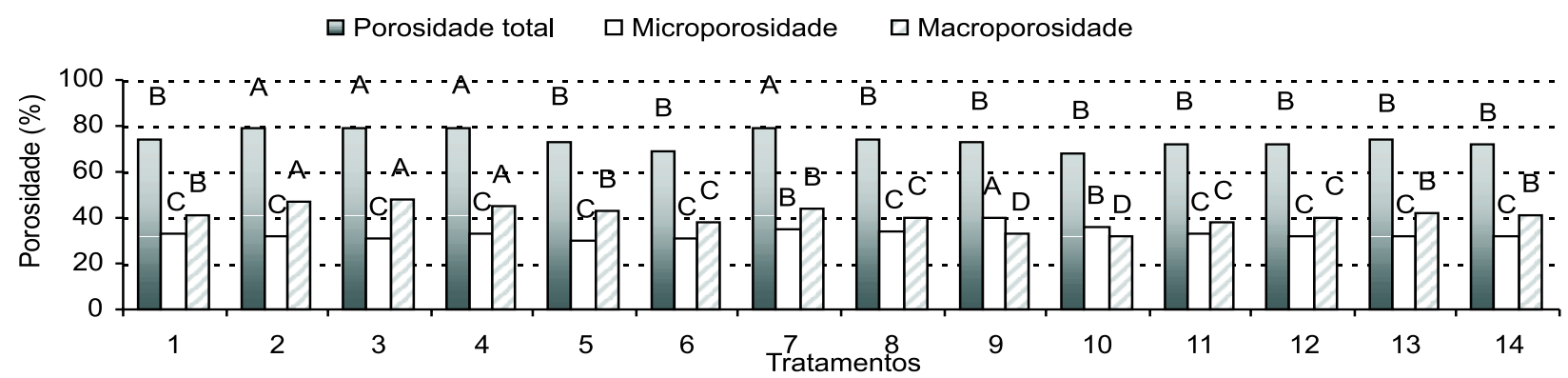

Figura 3 - Porosidade total, microporosidade e macroporosidade dos substratos estudados. Médias seguidas de uma mesma letra, para cada característica, não diferem entre si, pelo teste de Scott-knott a 5\% de probabilidade.

Figure 3 - Total porosity, microporosity and macroporosity for different treatments of studied substrates. Means followed by the same letters, for each characteristic, are not significantly different by the Scott-knott test, at 5\% probability. 
Quanto à microporosidade (Figura 3), os valores observados em todos os tratamentos se enquadraram como médios. Esses valores foram significativamente superiores no tratamento T9, seguido de T7 e T10.

Nos sistemas de produção de mudas em pequenos recipientes, as características físicas do substrato são fundamentais para um equilíbrio adequado entre os seus constituintes, de forma a prover adequada relação entre macro e microporosidade (LOPES et al., 2005). Com base nisso e observando-se os diferentes tratamentos, verificaram-se três grupos de relação de macro e microporosidade: de 0,80 a 0,90 (T9 e T10), de 1,15 a 1,30 (T1, T6, T7, T8, T11, T12, T13 e T14) e de 1,37 a 1,56 (T2, T3, T4 e T5). Pressupõe-se que nos tratamentos T9 e T10 a serragem e o esterco bovino, puros ou em adição à terra de subsolo, foram os responsáveis pela maior microporosidade. Entretanto, quando levada em conta a capacidade máxima de retenção de água (Figura 4), verifica-se que os tratamentos T9 e T10 são os que possuem menores valores, indo ao desencontro da teoria de Lopes et al. (2005). A mesma constatação também pôde ser observada no estudo desenvolvido por Almeida (2005).

No que tange à capacidade máxima de retenção de água (Figura 4), segundo a escala de Gonçalves e Poggiani (1996), observaram-se valores baixos nos tratamentos T9 (25,0\%), T10 (23,5\%) e T12 (30,8\%) e médios nos demais. Verificou-se superioridade significativa nos tratamentos T2 $(42,4 \%)$ e T3 $(42,5 \%)$, seguidos dos tratamentos T1 $(37,7 \%), \mathrm{T} 4(39,0 \%), \mathrm{T} 5$ $(35,7 \%)$ e T7 (36,7\%). Na seqüência, vêm os tratamentos T6 (32,2\%), T8 (31,7\%) e T11 $(29,2 \%)$ ao T14 $(31,9 \%)$ e, finalmente, os tratamentos T9 e T10. Resultados obtidos por Almeida (2005) com substratos diferentes variaram de 14,8 a 50,4\%. Para água disponível (Figura 4 ), puderam ser observados valores superiores a $4 \%$ nos tratamentos T1, T2 e T3; entre 2 e $4 \%$ nos tratamentos T4, T5, T7 e T8; e inferiores a $2 \%$ nos tratamentos T6, T9 а T14.

Com relação ao $\mathrm{pH}$ dos substratos onde predomina a matéria orgânica, a faixa ideal recomendada é de 5,0 a 5,8 e, quando for à base de solo mineral, entre 6,0 e 6,5 (KÄMPF, 2000). Segundo essa classificação, os resultados deste estudo (Tabela 2) indicam que os valores de pH nos tratamentos T1, T3, T5, T6 e T14 são considerados baixos, concordando com a classificação de Gonçalves e Poggiani (1996). Os demais são considerados adequados pela classificação de Kämpf (2000) e médios pela de Gonçalves e Poggiani (1996). Contudo, o valor de $\mathrm{pH}$ é variável em função da espécie e, segundo Dedecek (1997), a erva-mate ocorre naturalmente em solos ácidos, levando à conclusão de que os tratamentos estudados estão dentro de faixas de $\mathrm{pH}$ aceitáveis para a espécie.

A mortalidade das mudas aos 15 e 30 dias após a repicagem foi maior nos tratamentos $\mathrm{T} 1, \mathrm{~T} 2, \mathrm{~T} 4, \mathrm{~T} 5$ e T6 (Figura 5). Lourenço et al. (2000) concluíram que o esterco bovino é o melhor condicionador e a dose que fornece um terço do volume é suficiente para a composição de substratos para produção de mudas de erva-mate em sacos plásticos. No presente estudo, também se verificou que o esterco bovino é um bom componente de substrato para produção de mudas de erva-mate, resultando em baixa mortalidade de mudas.

$\square$ Capacidade máxima retenção de água $\square$ Água disponivel

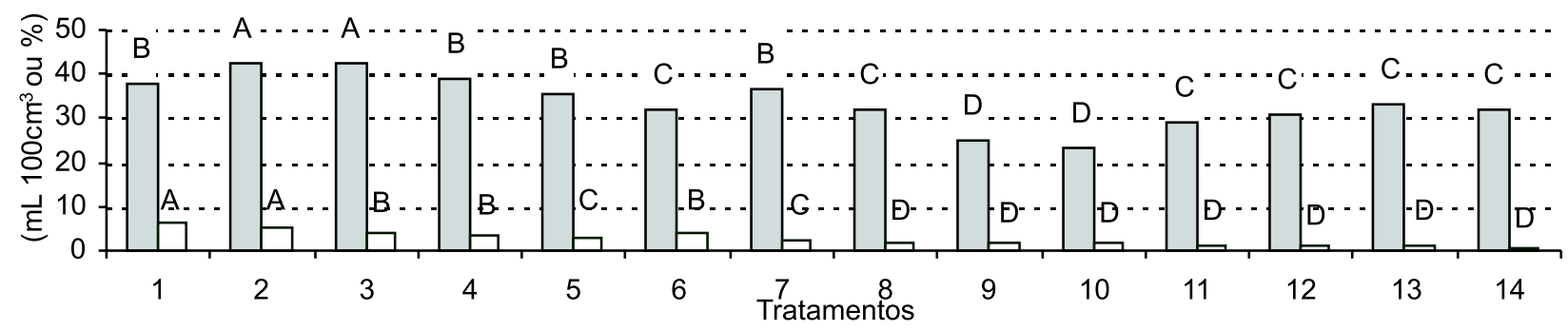

Figura 4 - Valores de capacidade máxima de retenção de água e água disponível dos substratos estudados. Médias seguidas de uma mesma letra, para cada característica, não diferem entre si, pelo teste de Scott-knott a 5\% de probabilidade.

Figure 4-Maximum capacity of water retention and available water for the studied substrates. Means followed by the same letters, for each characteristic, are not significantly different by the Scott-knott test, at 5\% probability. 


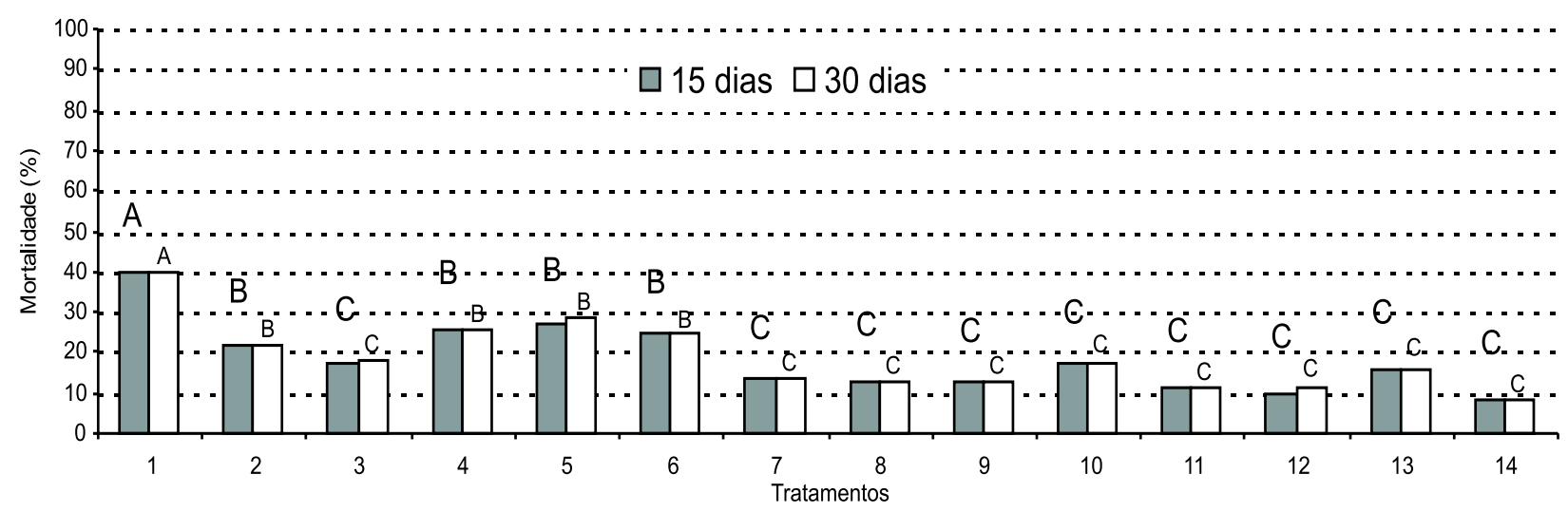

Figura 5 - Mortalidade de mudas de erva-mate (Ilex paraguariensis) aos 15 e 30 dias após a repicagem em função dos substratos. Médias seguidas de uma mesma letra, para cada característica, não diferem entre si, pelo teste de Scott-knott a $5 \%$ de probabilidade. Dados transformados em arco-seno $\sqrt{\left(\frac{X}{100}\right)}$.

Figura 5 -Mortality of Ilex paraguariensis seedlings at 15 and 30 days after transplanting as a function of the substrates. Means followed by the same letters, for each characteristic, are not significantly different by the Scott-knott test, at $5 \%$ probability. Data were transformed to arcsin values $\sqrt{\left(\frac{X}{100}\right)}$.

Os valores de diâmetro de colo das mudas ao sexto mês após a repicagem (Figura 6) se agruparam em duas classes, ou seja, T3, T4 e T14, como os menores valores (de 1,88 a 2,06 mm e média de 2,00 $\mathrm{mm}$ ) e os demais com maiores valores (de 2,20 a 2,71 mm e média de $2,44 \mathrm{~mm}$ ). Todos os tratamentos que se enquadraram na classe de menores valores apresentavam, em sua constituição, a serragem, associada com substrato comercial (SC) ou húmus de minhoca (HM), com $20 \%$ no T3, associada com $60 \%$ de SC e $20 \%$ de palito de erva-mate (PE); em $10 \%$ no T4, associada com $60 \%$ de SC, $20 \%$ de PE e $10 \%$ de terra de subsolo (TS); e em $40 \%$ no T14, associada com $20 \%$ de TS e $40 \%$ de HM. A ocorrência de menores diâmetros de colo nos substratos que continham serragem pode estar associada à menor capacidade de retenção de nutrientes durante o processo produtivo das mudas. Assim, esses valores poderiam ser aumentados com adubações de cobertura aplicadas no decorrer do processo produtivo das mudas de erva-mate.

Para a altura das mudas (Figura 6) observou-se destaque no tratamento T10 seguido por T6 e T2, com alturas de 13,9; 12,9; e 12,3 cm, respectivamente. Esses, porém, não apresentaram diferenças significativas em relação aos tratamentos T1, T7, T8, T9, T11, T12 e T13. Toledo (1992), estudando uma série de materiais (solo, areia, bagaço de cana, plantmax e húmus de minhoca) como substratos para a formação de mudas de laranjeira, concluiu que a mistura de $30 \%$ de solo, $40 \%$ de areia e $30 \%$ de húmus de minhoca foi a que apresentou maiores valores de altura e diâmetro das mudas. Segundo esse mesmo autor, a superioridade desse substrato foi devida aos benefícios do componente húmus.

Neste presente estudo, três dos quatro tratamentos em que se utilizou húmus de minhoca (T11, T12 e T13) não diferiram estatisticamente dos que obtiveram melhores resultados para altura. Gomes et al. (1991), estudando 83 tratamentos de substratos formulados com base em nove materiais diferentes, concluíram que as maiores alturas em mudas de Eucalyptus grandis aos 90 dias de idade se encontravam nos tratamentos que possuíam, em sua composição, uma fonte de matéria orgânica e a moinha de carvão.

A facilidade de retirada das mudas de erva-mate do tubete aos seis meses após a repicagem mostrouse de média a alta (Figura 7), não havendo diferenças destacadas entre os tratamentos. Essa é uma indicação muito importante na escolha do tipo de substrato a ser adotado na produção de mudas de erva-mate, visto que determina a rapidez de preparação das mudas antes do plantio ou venda, além de que, em substratos difíceis de serem retirados da embalagem, ocorre a desintegração do torrão formado. Notou-se uma boa agregação das raízes das mudas ao substrato no sexto mês após a repicagem (Figura 7), não havendo diferenças significativas entre os tratamentos estudados.

R. Árvore, Viçosa-MG, v.31, n.2, p.209-220, 2007 


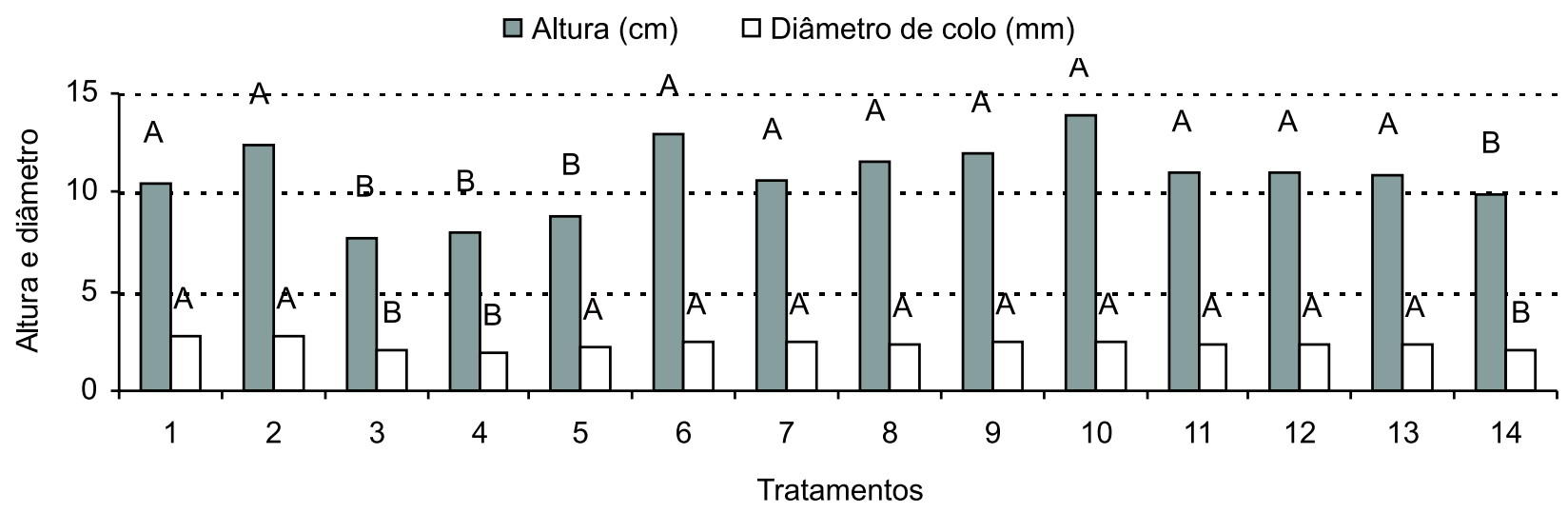

Figura 6 - Altura e diâmetro de colo das mudas de erva-mate (Ilex paraguariensis) em função dos substratos testados. Médias seguidas de uma mesma letra, para cada característica, não diferem entre si, pelo teste de Scott-knott a 5\% de probabilidade.

Figure 6 - Height and collar diameter of the Ilex paraguariensis seedlings as a function of the tested substrates. Means followed by the same letters, for each characteristic, are not significantly different by the Scott-knott test, at $5 \%$ probability.

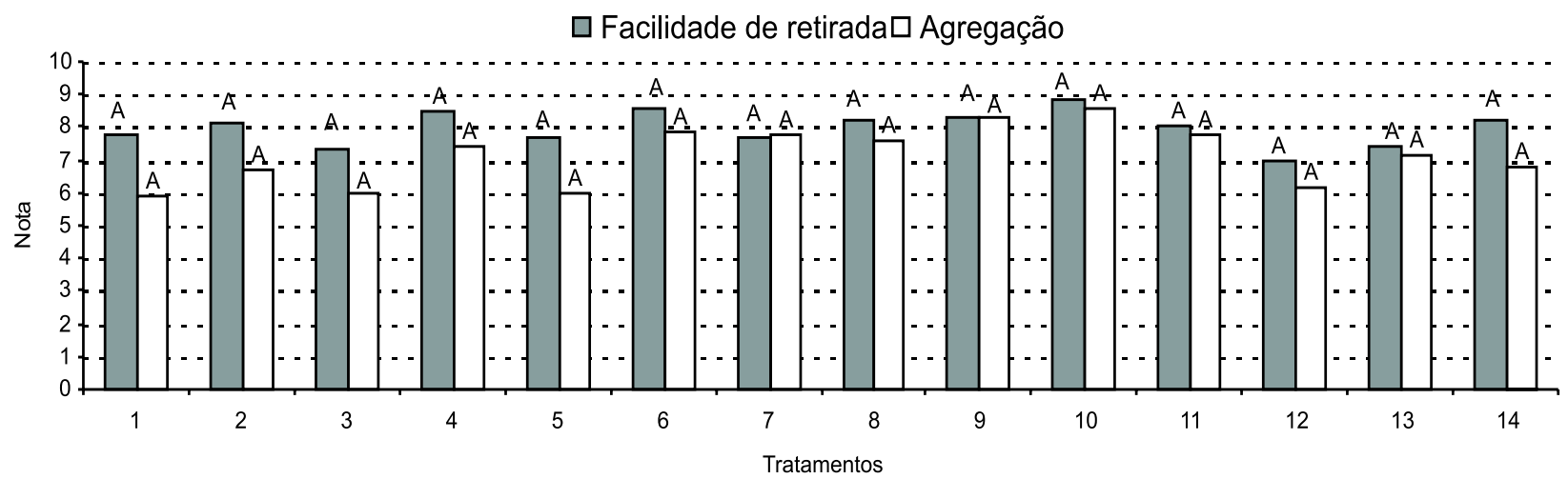

Figura 7 - Facilidade de retirada e agregação das raízes de erva-mate (Ilex paraguariensis) do tubete em resposta aos substratos testados. Médias seguidas de uma mesma letra, para cada característica, não diferem entre si, pelo teste de Scottknott a 5\% de probabilidade. Dados transformados em $\sqrt{X}$.

Figure 7 - Easiness of removal and aggregation of Ilex paraguariensis roots. Means followed by the same letters, for each characteristic, are not significantly different by the Scott-knott test, at $5 \%$ probability. Data were transformed to $\sqrt{X}$.

O tempo gasto para a limpeza de plantas indesejáveis até os seis meses após a repicagem sofreu variações de 1 a 4 horas para cada 1.000 mudas vivas (Figura 8). Em geral, os tratamentos T7 ao T14 apresentaram menor presença de plantas indesejáveis. Os tratamentos com substrato comercial em sua composição (T1 ao T6) apresentaram mais plantas indesejáveis, denotando a falta de qualidade desse material quanto a essa característica.

R. Árvore, Viçosa-MG, v.31, n.2, p.209-220, 2007
Conforme pode ser visualizado na Tabela 3, a densidade global apresentou correlações negativas com a porosidade total $(\mathrm{P}<0,01)$, macroporosidade, capacidade de retenção de água e água disponível $(\mathrm{P}<0,05)$. A porosidade total apresentou correlação positiva com a macroporosidade, capacidade de retenção de água $(\mathrm{P}<0,01)$ e água disponível $(\mathrm{P}<0,05)$ e negativas com a altura das mudas $(\mathrm{P}<0,05)$. Já a microporosidade teve correlação negativa com a 
macroporosidade $(\mathrm{P}<0,01)$ e capacidade de retenção de água $(\mathrm{P}<0,05)$ e positivas com a agregação das mudas ao substrato $(\mathrm{P}<0,01)$. A macroporosidade mostrou correlação positiva com a capacidade de retenção de água $(\mathrm{P}<0,01)$, com água disponível, e negativa com altura das mudas, agregação ao substrato $(\mathrm{P}<0,01)$ e facilidade de retirada das mudas do tubete $(\mathrm{P}<0,05)$. Comparando com dados de literatura, em que a microporosidade é citada como o espaço ocupado pela água (MARTINEZ, 2002; LOPES et al., 2005), com os resultados de correlação dneste estudo observouse uma inversão, ou seja, a macroporosidade como sendo a responsável pela retenção de água e água disponível. Isso pode ser em função do fato de os valores de macroporosidade serem maiores do que os de micro para a maioria dos substratos estudados.

Em relação à capacidade máxima de retenção de água (Tabela 3), observaram-se correlações positivas com água disponível $(\mathrm{P}<0,01)$ e negativas com altura das mudas $(\mathrm{P}<0,05)$ e agregação ao sistema radicular $(\mathrm{P}<0,01)$. A água disponível apresentou correlações positivas com sobrevivência aos 15 e 30 dias $(\mathrm{P}<0,01)$. A sobrevivência aos 15 dias teve correlações positivas, com sobrevivência aos 30 dias $(\mathrm{P}<0,01)$.

Para a altura das mudas aos seis meses após a repicagem (Tabela 3) observou-se correlação positiva com o diâmetro, agregação ao substrato $(\mathrm{P}<0,01)$ e facilidade de retirada das mudas $(\mathrm{P}<0,05)$. Como a agregação do sistema radicular ao substrato depende exclusivamente do volume e estrutura das raízes, supõe- se uma correlação positiva dessas características com a altura e diâmetro de colo das mudas.

A facilidade de retirada das mudas do tubete (Tabela 3) mostrou correlação positiva $(\mathrm{P}<0,01)$ com a agregação do sistema radicular das mudas ao substrato, denotando que um substrato que promova uma boa agregação das raízes resulta em melhorias no processo de embalagem e expedição das mudas produzidas para o local de plantio definitivo.

De maneira geral, observando as correlações (Tabela 3 ), pode-se depreender que, para a produção de mudas de erva-mate com maior altura aos seis meses após a repicagem (em tubetes), é preciso utilizar substratos com menor porosidade total, menor macroporosidade e menor capacidade máxima de retenção de água. Nesse sentido, também ressalta-se que a maior altura das mudas resulta em maior facilidade de retirada delas dos tubetes e maior agregação do sistema radicular. Já para a obtenção de maiores valores de sobrevivência aos 15 e 30 dias após a repicagem devem-se priorizar substratos que apresentem maior porcentagem de água disponível. Para a facilidade de retirada das mudas dos tubetes, devemse priorizar substratos com menor macroporosidade e, por fim, para melhor agregação, priorizar substratos com maior microporosidade, menor macroporosidade e menor capacidade de retenção de água.

Os resultados de correlação das características químicas e as variáveis de crescimento não foram apresentadas em vista de sua baixa significância verificada.

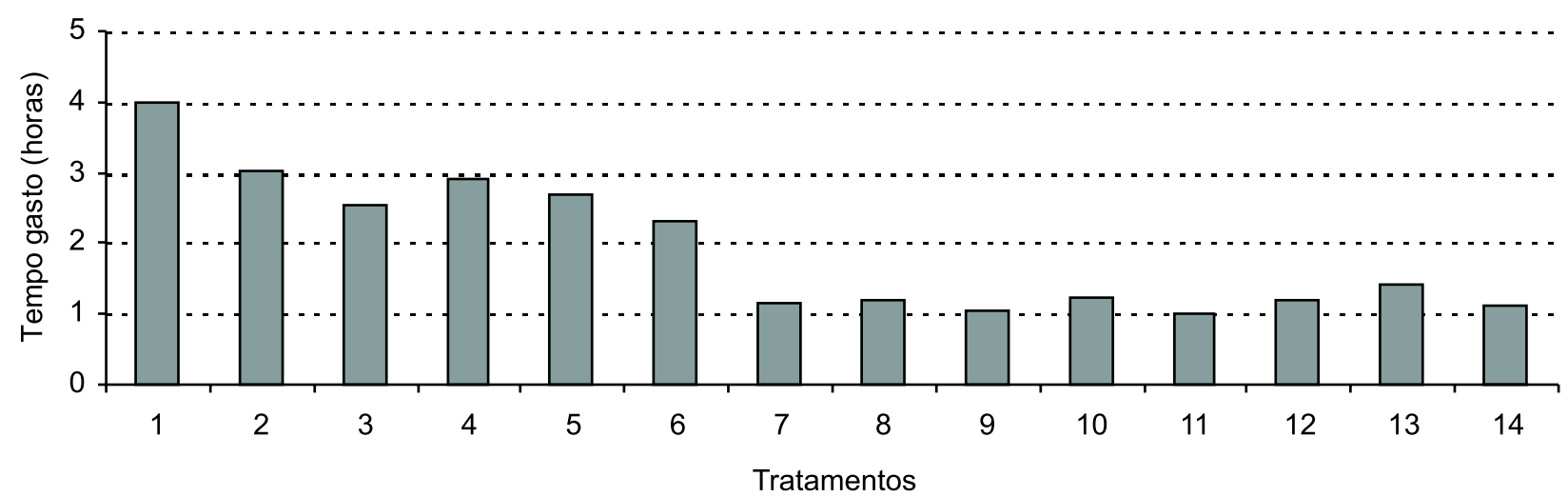

Figura 8 - Tempo, em horas, para limpeza de plantas indesejáveis em 1.000 mudas de erva-mate vivas até os seis meses após a repicagem, em função dos diferentes tratamentos dos substratos testados.

Figure 8 - Time, in hours, for cleaning of undesirable plants in 1000 alive Ilex paraguariensis seedlings up to six months after transplanting as a function of the different substrate treatments. 
Tabela 3 - Correlações de Pearson para as características físicas dos substratos e de crescimento de mudas de erva-mate (Ilex paraguariensis)

Table 3 - Pearson's correlations for substrate physical characteristics and Ilex paraguariensis seedling growth.

\begin{tabular}{|c|c|c|c|c|c|c|c|c|c|c|c|c|}
\hline & Dglobal & Ptotal & Microp & Macrop & Capret & Adisp & Sob15 & Sob30 & Alt & $\mathrm{Dc}$ & Faret & Agreg Tempo \\
\hline$\overline{\text { Dglobal }}$ & 1,00 & & & & & & & & & & & \\
\hline Ptotal & $-0,70 * *$ & 1,00 & & & & & & & & & & \\
\hline Microp & $-0,10^{\mathrm{ns}}$ & $-0,13^{\mathrm{ns}}$ & 1,00 & & & & & & & & & \\
\hline Macrop & $-0,50 *$ & $0,85 * *$ & $-0,63 * *$ & 1,00 & & & & & & & & \\
\hline Capret & $-0,58 *$ & $0,82 * *$ & $-0,60 *$ & $0,96 * *$ & 1,00 & & & & & & & \\
\hline Adisp & $-0,59 *$ & $0,48 *$ & $-0,28^{\mathrm{ns}}$ & $0,51 *$ & $0,72 * *$ & 1,00 & & & & & & \\
\hline Sob15 & $-0,35^{\mathrm{ns}}$ & $0,14^{\mathrm{ns}}$ & $-0,24^{\mathrm{ns}}$ & $0,23^{\mathrm{ns}}$ & $0,44^{\mathrm{ns}}$ & $0,83 * *$ & 1,00 & & & & & \\
\hline Sob30 & $-0,35^{\mathrm{ns}}$ & $0,13^{\text {ns }}$ & $-0,26^{\mathrm{ns}}$ & $0,24^{\mathrm{ns}}$ & $0,45^{\text {ns }}$ & $0,82 * *$ & $1,00 * *$ & 1,00 & & & & \\
\hline Alt & $0,30^{\mathrm{ns}}$ & $-0,59^{*}$ & $0,45^{\mathrm{ns}}$ & $-0,69 * *$ & $-0,61 *$ & $-0,16^{\mathrm{ns}}$ & $-0,14^{\mathrm{ns}}$ & $-0,16^{\mathrm{ns}}$ & 1,00 & & & \\
\hline Dc & $-0,21^{\mathrm{ns}}$ & $-0,20^{\mathrm{ns}}$ & $0,25^{\mathrm{ns}}$ & $-0,29^{\mathrm{ns}}$ & $-0,14^{\mathrm{ns}}$ & $0,32^{\mathrm{ns}}$ & $0,25^{\mathrm{ns}}$ & $0,23^{\mathrm{ns}}$ & $0,73 * *$ & 1,00 & & \\
\hline Faret & $0,24^{\mathrm{ns}}$ & $-0,31^{\mathrm{ns}}$ & $0,40^{\mathrm{ns}}$ & $-0,46^{*}$ & $-0,36^{\mathrm{ns}}$ & $0,03^{\text {ns }}$ & $0,14^{\mathrm{ns}}$ & $0,10^{\mathrm{ns}}$ & $0,46^{*}$ & $0,02^{\mathrm{ns}}$ & 1,00 & \\
\hline Agreg & $0,26^{\mathrm{ns}}$ & $-0,34^{\mathrm{ns}}$ & $0,71 * *$ & $-0,64 * *$ & $-0,66 * *$ & $-0,44^{\mathrm{ns}}$ & $-0,36^{\mathrm{ns}}$ & $-0,39^{\mathrm{ns}}$ & $0,62 * *$ & $0,10^{\mathrm{ns}}$ & $0,70^{* *}$ & 1,00 \\
\hline Tempo & $-0,44^{\mathrm{ns}}$ & $0,38^{\mathrm{ns}}$ & $-0,42^{\mathrm{ns}}$ & $0,52 *$ & $0,71 * *$ & $0,92 * *$ & $0,92 * *$ & $0,92 * *$ & $-0,34^{\mathrm{ns}}$ & $0,12^{\text {ns }}$ & $-0,02^{\mathrm{ns}}$ & $-0,58 * 1,00$ \\
\hline
\end{tabular}

$* *$ e $*$ significativos a $1 \%$ e $5 \%$, respectivamente; e ns = não significativo.

DGLOBAL = densidade global; PTOTAL = porosidade total; MICROP = microporosidade $;$ MACROP $=$ macroporosidade $;$ CAPRET $=$ capacidade máxima de retenção de água; $\mathrm{ADISP}=$ água disponível; SOB15 = sobrevivência 15 dias após a repicagem; SOB30 = sobrevivência 30 dias após a repicagem; ALT = altura das mudas aos seis meses após a repicagem; DC = diâmetro do coleto das mudas aos seis meses após a repicagem; FARET = facilidade de retirada das mudas do tubete; AGREG = agregação das raízes ao substrato; e TEMPO = tempo gasto, em horas, para a limpeza de plantas invasoras em 1.000 mudas de erva-mate.

\section{CONCLUSÃO}

Com base nos objetivos propostos e nas condições em que foi realizado este estudo, pode-se concluir que:

$\S$ Os substratos contendo esterco bovino, serragem e palito de erva-mate se mostraram adequados para a produção de mudas de erva-mate.

$\S$ O substrato composto de $40 \%$ de esterco bovino e $60 \%$ de serragem se destacou, em vista da boa relação custo-benefício apresentada e da sua facilidade de preparo, embora necessite de ajustes na nutrição para maiores crescimentos.

$\S$ As características químicas dos substratos não interferiram em suas características físicas, nem nas variáveis de sobrevivência e crescimento das mudas até os seis meses após a repicagem.

$\S$ A influência das diferentes características físicas dos substratos na produção de mudas de erva-mate depende da variável analisada.

\section{AGRADECIMENTOS}

À Empresa Baldo S.A., pelos suportes estrutural e financeiro às pesquisas que deram origem a este trabalho.

R. Árvore, Viçosa-MG, v.31, n.2, p.209-220, 2007

\section{REFERÊNCIAS}

ALMEIDA, L. S. Avaliação morfológica de mudas de Allophylus edulis (A. St.Hil., A. Juss. \& Cambess.) Radl. (Vacum) e Schinus terebinthifolius Raddi (Aroeira) produzidas em diferentes substratos. 2005. 96f. Dissertação (Mestrado em Ciências Florestais) - Universidade Federal do Paraná, Curitiba, 2005.

ANDRADE NETO, A.; MENDES, A. N. G.; GUIMARAES, P. T. G. Avaliação de substratos alternativos e tipos de adubação para a produção de mudas de cafeeiro (Coffea arabica L.) em tubetes. Ciência e Agrotecnolgia, v.23, n.2, p.270-280, 1999.

CARRIJO, O. A.; LIZ, R. S.; MAKISHIMA, N. Fibra de casca de coco verde como substrato agrícola. Horticultura Brasileira, v.20, n.4, p.533-535, 2002.

DEDECEK, R. A. Manejo de solos em ervais. In: CONGRESSO SUL-AMERICANO DAERVA-MATE, 1.; REUNIAO TECNICA DO CONE SUL SOBRE A CULTURA DA ERVA-MATE, 2., 1997, Curitiba. Anais... Colombo: Embrapa-CNPF, 1997. p.317336. (Embrapa-CNPF. Documentos, 33). 
EMPRESA BRASILEIRA DE PESQUISA AGROPECUÁRIA - EMBRAPA. Centro Nacional de Pesquisa de Solos. Manual de Métodos de Análise de Solo. Rio de Janeiro: Embrapa Solos, 1997. v.1, 210p.

FERRON, R. M. Produção de mudas de erva-mate em tubetes plásticos. In: CONGRESSO SULAMERICANO DA ERVA-MATE, 1.; REUNIAO TECNICA DO CONE SUL SOBRE A CULTURA DA ERVA-MATE, 2., 1997, Curitiba. Anais... Colombo: Embrapa-CNPF, 1997. p.153-172. (Embrapa-CNPF. Documentos, 33).

FOnSECA, T. G. Produção de mudas de hortaliças em substratos de diferentes composições com adição de $\mathrm{CO}_{2}$ na água de irrigação. 2001. $72 \mathrm{f}$. Dissertação (Mestrado em Agronomia) - Escola Superior de Agricultura "Luiz de Queiroz", Piracicaba, 2001.

FREITAS, T. A. S. et al. Mudas de eucalipto produzidas a partir de miniestacas em diferentes recipientes e substratos. Revista Arvore, v.30, n.4, p.519-528, 2006.

KÄMPF, A. N. Produção comercial de plantas ornamentais. Guaíba: Agropecuária, 2000. 254p.

GOMES, J. M. et al. Efeito de diferentes substratos na produção de mudas de Eucalyptus grandis W. Hill ex- Maiden, em "Win-Strip".

Revista Arvore, v. 15, n.1, p.35-42, 1991.

GONÇALVES, J. L. M.; POGGIANI, F. Substratos para produção de mudas florestais. In: CONGRESSO LATINO AMERICANO DE CIÊNCIA DO SOLO, 13., 1996. Águas de Lindóia. Anais... Águas de Lindóia: 1996. CD-ROM.

LOPES, J. L. W. et al.. Efeitos da irrigação na sobrevivência, transpiração e no teor relativo de água na folha em mudas de Eucalyptus grandis em diferentes substratos. Scientia Forestalis, n.68, p.97-106, 2005.
LOURENÇO, R. S. et al. Influência do substrato no desenvolvimento de mudas de erva-mate (Ilex paraguariensis). Perspectiva, v.24, n.88, p.81-99, 2000.

MARTÍNEZ, P. F. Manejo de substratos para horticultura. In: FURLANI, A. M. C.

Caracterização, manejo e qualidade de substratos para produção de plantas. Campinas: Instituto Agronômico, 2002. 122p. (Documentos IAC, 70).

MEDEIROS, A.C. S. Dormência em sementes de erva-mate (Ilex paraguariensis St. Hil.). Colombo: Embrapa-CNPF, 1998. 25p. (Embrapa-CNPF. Documentos, 36).

MOSELE.S. H.; RODIGHERI, H. R.; PENTEADO

JUNIOR, J. Diagnóstico da erva-mate no Alto Uruguai Gaúcho. Perspectiva, v.18, n.64, p.7-17, 1994.

SANTIN, D. et al. V. Uso de substratos alternativos com solo no desenvolvimento inicial de mudas de erva-mate (Ilex paraguariensis) St. Hill.). In: SIMPÓSIO LATINO-AMERICANO SOBRE MANEJO FLORESTAL, 3., 2004, Santa Maria. Anais... Santa Maria: Universidade Federal de Santa Maria, 2004. p.200-205.

SANTOS, C. B. et al. Efeito do volume de tubetes e tipos de substratos na qualidade de mudas de Cryptomeria japonica (L.F.) D.Don. Ciência Florestal, v.10, n.2, p.1-15, 2000.

SANTOS, D. S. B. et al. Efeito do substrato e profundidade de semeadura na emergência e desenvolvimento de plântulas de sabia. Revista Brasileira de Sementes, v.16, n.1, p.50-53, 1994.

Sturion, J. A. Produção de mudas e implantação de povoamentos com erva-mate. Curitiba: Embrapa CNPF, 1988. (Circular Técnica, 17).

TOLEDO, A, R. M. Efeito de substratos na formação de mudas de laranjeira (Citrus sinensis) em vaso. 1992. 88f. Dissertação (Mestrado em Fitotecnia) Universidade Federal de Lavras, Lavras, 1992. 